\title{
IMPLEMENTASI KEBIJAKAN PENATAUSAHAAN ASET TETAP BARANG MILIK NEGARA PADA KEPOLISIAN DAERAH KALIMANTAN TENGAH
}

\author{
Implementation Of State Assets Of State-Owned Goods Policy On The Policy \\ Of The Central Kalimantan
}

\section{Noor Hidayat* \\ Deni Patri Nasrani Sitepu}

Universitas Muhammadiyah Palangkaraya, Palangka Raya, Central Kalimantan, Indonesia

email: noor.hidayat@umpalangkaraya.ac..id

\begin{abstract}
Abstrak
Penelitian ini bertujuan untuk mngetahui, menjelaskan, dan mendeskripsikan Implementasi Kebijakan Penatausahaan Aset Tetap Barang Milik Negara Pada Kepolisian Daerah Kalimantan Tengah. Jenis penelitian yang digunakan dalam penelitian ini adalah deskriptif dengan pendekatan kualitatif menggunakan data yang berdasarkan fakta yang didapatkan di lapangan. Jenis data data primer yaitu pimpinan dan staf Kepolisian Daerah Kalimantan Tengah, Operator SIMAK BMN, Kepala Seksi Pelayanan Kekayaan Negara Kementerian Keuangan Palangka Raya. Sedangkan data sekunder berasal dari hasil dokumentasi dalam sumber pustaka. Teknik pengumpulan data menggunakan observasi, wawancara dan dokumentasi. Berdasarkan hasil analisis data yang didapatkan diketahui bahwa implementasi Kebijakan Penatausahan Aset Tetap Barang Milik Negara pada Polda Kalteng belum terlaksana dengan optimal karena komunikasi, disposisi, sumber daya dan struktur birokrasi yang belum maksimal.
\end{abstract}

Kata Kunci:

Implementasi

Kebijakan

Aset Tetap

Barang Milik Negara

Keywords:

Implementation

policies

Fixed Assets

State Property

\section{Accepted}

Januari 2015

\begin{abstract}
This study aims to find out, explain, and describe the Implementation of State-Owned Property Assets Administration Policy in the Central Kalimantan Regional Police. The type of research used in this study is descriptive with a qualitative approach using data based on facts obtained in the field. The primary data type is the Central Kalimantan Regional Police chief and staff, Operator SIMAK BMN, Head of the Ministry of Finance Palangka Raya's Wealth Services Section. While secondary data comes from the results of documentation in library sources. The technique of collecting data uses observation, interviews, and documentation. Based on the results of the analysis of the data obtained, it is known that the implementation of the Administration of Fixed Assets of State Property in the Central Kalimantan Regional Police has not been carried out optimally because of communication, disposition, resources and bureaucratic structures that have not been maximized.
\end{abstract}

\section{Published}

April 2015

\section{PENDAHULUAN}

Barang milik negara memiliki peran yang sangat penting dalam mendukung pelaksanaan kegiatan pemerintah. Barang milik negara tersebut sebagian besar diperoleh dari anggaran APBN yang notabene menggunakan uang rakyat sehingga pertanggung jawaban Penatausahan Barang Milik Negara yang sesuai dengan peraturan perundang-undnagan mutlak diperlukam untuk meningkatkan akuntabilitas dan transparansi dalam pengelolaan keuangan negara.
Selain itu pemerintah berkewajiban menyampaikan dan mempertanggung jawabkan Laporan Keuangan Pemerintah Pusat (LKPP), Laporan Arus Kas (LAK), Catatan Atas Laporan Keuangan (CALK) kepada Dewan Perwakilan Rakyat (DPR). Dimana inromasi Barang milik ngera yang terdapat dalam neraca yang terdiri dari pos persediaan, aset tetap, maupun asetaset lainnya berasal dari laporan. Oleh karena itu, pertanggungjawaban pentausahaan barnag milik ngera milik peran yang penting dalam keuangan negara. 
Kepolisan Daerah Kalimantan Tengah adalah satu pengguna barang yang merupakan perpanjangan tangan dari Kepolisian Negara Republik Indonesia yang berkedudukan sebagai Unit Akutansi Kuasa Pengguna Barang. Dari hasil observasi peneltiian ditemukan adnaya kelemahan dalam pengelolaan keuangan dan penatausahaan aset tetap barang milik negara terkait dengen pembukuan, inventarisasi dan peloran aset. Lemahnya komunikasi di dalam birokrasi, sikap perilaku dan sumber daya yang belum memadai sehingga kurnag memahami tata cara penatausahan barnag milik negara.

Implementasi merupakan salah satu tahap dalam proses kebijakan publik. Biasnaya implementasi dilaksnakan setelah sebuah kebijakan dirumuskan dengen tujuan yang jelas. Implementasi adlah sebagai tidnakan-tidnakan yang dilakukan oleh baik individu/pejabat atau kelompok pemerintah atau swasta yang diarahkan pada pencapaian tujuan0tujuan yang telah digariskan dalam kebijakan (Tahir,20I4:54). Kemudian Impelmentasi kebijakan merupakan tahap yang krusial dlama proses kebijakan publik. Suatu progran kebijakan harus diimplementasikan agar mampunyai dampak dn tujuaan yang diinginkan. Implementasi dipandang secar luas mempunyai makna pelaksanaan undang-undang dimana berbagai aktor, organisasi, prosedur dan tkenik bekerja bersam-sama untuk menjalankan kebijakan dalam upaya untuk meraih tujuan-tujuan kebijakan atau program-program. (Winarno,20।4:146).

Menurut Edward III (Nugroho, 20I4: 225-226) terdapat empat faktor yang beperan penting dalam pencapaian keberhasilan implementasi atau kegagalan implementasi kebijakan yaitu :

I. Komunikasi

2. Sumber Daya

3. Disposisi

4. Struktur Birokrasi
Penatausahaan Aset Tetap Barang Milik Negara

Penatausahaan adalah rangkaian kegiatan yang meliputi pembukaan, inventarisasi, dan pelporan BMN/D sesuai dengan ketertentuan yang berlaku. PP RI Nomor 27 Tahun 2014 tentang Pengelolaan Barang Milik Negara menjadi dasar untuk hukum dalam penatausahaan aset $\mathrm{BMN}$.

\section{METODOLOGI}

Jenis penelitian yang digunakan dalam penelitian ini adalah deskriptif dengan pendekatan kualitatif menggunakan data yang berdasarkan fakta yang didapatkan di lapangan. Jenis data data primer yaitu pimpinan dan staf Kepolisian Daerah Kalimantan Tengah, Operator SIMAK BMN, Kepala Seksi Pelayanan Kekayaan Negara Kementerian Keuangan Palangka Raya. Sedangkan data sekunder berasal dari hasil dokumentasi dalam sumber pustaka. Teknik pengumpulan data menggunakan observasi, wawancara dan dokumentasi.

\section{HASIL DAN PEMBAHASAN}

Berdasarkan hasil penelitian, dalam penatausahaan aset tetap BMN selalu melakukan komunikasi dan kordinasi pelaksanaan impelementasi kebijakan belum dipahami oleh peksanan pada pelaksanan kebijakan belum pernah memiliki buku peraturan tersebut yang menjadi petunjuk dalam pelaksanaan kebijakan hanya mendengar sepintas saat sosialisasi. Masih minimnnya pemhamam dair pelaksanaan terhadap Peraturan Perundang-Undangan yang berlaku mengakibatkan penatausahaan aset tetap BMN belum terlaksana dengan baik. Komunikasi dlaam hal ini adalah para pejabat harus berperan untuk menyampaikan kebijakan dengan baik. Hasil pengamatan langsug yang dilakukan terhdap bidang Kedokteran dan Kesehatan Polda Kalteng menunjukan bahwa pembinaan fungsi penatausahaan aset tetap BMN yaitu biro saran dan prasarana polda kalteng terus memberikan informasi melalui kegaitan sosialisasi. 
Namun terlihat bahwa perlaksanaan penatausahaan aset tetap BMN belum optimal hal ini disebabkan oleh minimnya kemauan dari personel sebagai pelaksana kebijakan. Hal ini mnyebabkan pelaksana kebijakan belum berjalan sebagaimana mestinya. Kemudian pehamaham implementor juga masih mini, hal ini disebabkan oleh belaum adanya pendidikan dan pelatihan khusus bagi semua pelaksana. Selama ini pernah mendapatkan pelatihan dan pendidikan tapi hanya operator Sistem Informasi Manajemen Akuntansi Keuangan Barang Milik Negara (SIMAK $\mathrm{BMN})$.

Dalam implementasi kebijakan personel atau staf merupakan sumber yang paling penting. Walaupun jumlah staf tidak selalu mempunyai efek positif bagi implementasi kebijakan. Hal ini berarti bahwa jumlh staf yang banyak tidak otomatis mendorang implementasi yang berhasill. Hal ini kurangnnya kecakapan yang dimiliki oleh para pegawai atau personel. Namun disisi lain kekurangan staf juga akan menimbulkan persoalan yang pelik menyangkut implementasi yang efektif. Salah satu masalah yang dihadapi suatu kerja Kepolisian Daerah Polda Kalteng adalah tidak adannya pejabat pertama baik personel Polri yang berpangkat perwira pertama atau PNS uang bergolongan tiga yang memmpunyai kemmapuan dan keterampilan penatausahaan aset tetap BMN. Selain indikator staf, fasilitas fisik merupakan faktor penting dalam implementasi kebijakan. Peran fasilitas sangat penting karena tanpa adanya saran dan prasaran yang memadai bagaumana personel pelaksanaan kebijakan dapat melaksanakan tugas dengan baik.

Struktur organisasi yang melaksankan kebijakan memiliki perngaruh penting pada implementasi. Salah satu dari aspek struktural paling dasr dari suatu organisasi adalah prosedur-prosedur kerja (SOP). Dengan menggunakan SOP, para pelaksana dapat memanfaatkan waktu yang tersedia. Melihat struktur birokrasi yang ada di Polda Kalteng tidak ada yang ditunjuk pejabat struktural atau pimpinan menegah yang menguasai atau memahami tentang pematausahaan tentan penatausahan aset tetap BMN. Yang ada hanya pegawai negeri Sipil golongan dua dan anggota Polri yang berpangkat bintara yang menjalankan tugas sebagai pengelolaan sekaligus sebagai pelaksanaan dari kebijakan. Pekerjaan yang berat bagi personel untuk menjalankan tugas sebagai pengelola penatausahaan karena perlu tanggung jawab yang besar.

Kurangnnya informasi dari para pejabat seringkali merupakan sebab kekaburan dalam perintah-perintah implementasi. Presepsi-presepsi dari para pelaksana terhadap komunikasi-komunikasi implementasi mungkin dihambat oleh kurangnnya waktu untuk memberikan perhatian yang penuh kepada perintahperintah. SOP pada padasrnya merupakan sebagian reaksi terhadpa sumber-sumber yang terbatas.

\section{KESIMPULAN}

Dari hasil pembahasan dalam penelitian ini, maka dapat disimpulkan bahwa beberapa hal mengenai implementasi kebijakan penatausahaan aset tetap barang milik negara di Kepolisian Daerah Kalteng sebagai berikut :

I. Komunikasi melalui sosialisasi Peraturan belum terlaksana secara menyeluruh bagi personel pelaksana penatausahaan barnag milik negara Polda kalteng.

2. Belum adnaya komitmen yang tinggi dari pelaksanan kebijakan implementasi kebijakan penatausahan barang milik negara di Polda Kalimantan Tengah hal ini dapat dilihat dari kurangnya dukung dari personel pelaksana teknis kegiataan.

3. Keterbatasan sumber daya manusia yang memiliki kemampuan dalam penatausahaan aset teap barnag milik negara. 
4. Kepolisian Daerah Kalteng belum memiliki struktur birokrasi yang jelas dalam penatausahaan aset tetap barnag milik negara di setiap satuan kerja, belum adanya personel yang menduduki jabatan struktural tingkat pimpinan menengah yang memahami dan menguasai tentang penatausahaan aset barang milik negara.

\section{REFERENSI}

Anggara, Sahya. 20I4. Kebijakan Publik. Bandung: CV Pustaka Setia.

Agustino, Leo. 2012. Dasar-Dasar Kebijakan Publik. Bandung : CV. Alfabeta.

Dunn, willian N. 200I3. Analisis Kebijakan Publik. Yogyakarta : Gajah Mada university press.

Herabudin. 20I4. Studi Kebijakan Pemerintah dari Filosofi ke Implementasi. Bandung: Pustaka Setia.

Hamdi, Muchlis. 20I4. Kebijakan publik (proses, analisis dan partisipasi). Bogor. Ghalia Indonesia.

Nugroho, Riant. 2014. Kebijakan Publik di Negaranegara Berkembang. Yogyakarta : Pustaka Pelajar.

Peraturan Pemerintah Nomor 27 Tahun 2014 Tentang Barnag Milik Negara/ Daerah.

Peraturan Menteri Keuangan Nomor 120 tahun 2007 tentang Penatausahaan Barang Milik Negara.

Peraturan Kepala Kepolisan Negara Republik Indonesia Nomor II Tahun 2003 tentang Mekanisme Pengelolaan Hibah di Lingkungan Kepolisian Negera Republik Indonesia.

Purwanto, Erwa Agus. 2013. Implementasi Kebijakan Publik. Yogyakarta : UGM.

Subarsono. 2013. Analisis Kebijakan Publik, Teori dan Aplikasi. Yogyakarta : Pustaka Pelajar.

Tahir, Arifin. 2014. Kebijakan publik \& Transparansi Penyelenggaraan Pemerintah Daerah. Bandung : Alfabeta.

Wahab, Solichin Abdul. 20II. Analisis Kebijakan Publik. Jakarta.

Winarno, Budi. 20I4. Kebijakan Publik (teori, proses dan studi kasus). Yogyakarta : Center of Acacemic Publishing Service. 